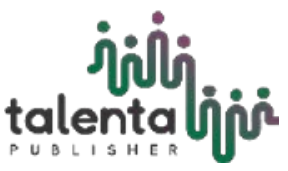

Jurnal Dinamis

Vol. 9, No. 2, Bulan Tahun |12-21

ISSN : 0216-7492, e-ISSN : 2809-3410

Homepage : https://talenta.usu.ac.id/dinamis

\title{
DESAIN DAN ANALISA DRONE PENYEMPROT PESTISIDA DENGAN KAPASITAS PENYEMPROTAN 0,5 LITER/MENIT
}

\author{
Ahmad Yunus Nasution ST.,MT. ${ }^{*}$ Azmi Muhammad ${ }^{2}$ \\ Departemen Teknik Mesin,Fakultas Teknik Universitas Sumatera Utara ${ }^{1}$ \\ Jurusan Teknik Mesin,Falkultas Teknik Universitas Muhammadiyah Jakarta² \\ *Email: ahmadjunusa@usu.ac.id
}

\begin{abstract}
ABSTRAK
Pada perkembangan zaman ini, kemajuan teknologi berkembang dengan pesat sehingga persaingan didalam dunia industri sendiri menuntut agar adannya peningkatan inovasi guna mendukung peningkatan produksi sebuah produk dan dengan adanya kemajuan teknologi dapat membantu meringankan pekerjaan bagi masyarakat. Salah satunya dengan memanfaatkan drone sebagai alat penyemprot pestisida. Sehingga dapat menghemat waktu proses penyemprotan pestisida pada lahan pertanian. Penelitian ini bertujuan untuk mendesain dan menghitung konstruksi Alat Penyemprot Pestisida dengan kapasitas penyemprotan 0,5 liter/menit. Dalam penelitian Desain dan Perhitungan Konstruksi Rangka Alat Penyemprot Pestisida Dengan Kapasitas Penyemprotan 0,5 liter / menit, peneliti harus merubah desain awal Alat Penyemprot Pestisida yang dimana pada awalnya menggunakan 6 lengan, diubah menjadi 4 lengan dengan menyesuaikan kemampuan dari motor brushless. Rangka Alat penyemprot Pestisida ini menggunakan center body berbentuk persegi delapan dengan ukuran $200 \mathrm{~mm} x$ $190 \mathrm{~mm}$ x $2 \mathrm{~mm}$, lengan dengan panjang $200 \mathrm{~mm}$ dan diameter $16 \mathrm{~mm}$, dan jarak antar motor ke motor ialah $600 \mathrm{~mm}$. Dalam proses pemilihan bahan, dilakukan perhitungan terhadap hasil rancangan Alat Penyemprot Pestisida, seperti tegangan, regangan, distribusi beban dan deformasi. Hal ini dilakukan untuk mengetahui kekuatan dari rancangan rangka Alat Penyemprot Pestida dan mendapatkan hasil bahwa hasil rancangan tersebut telah layak untuk digunakan. Material yang digunakan pada Alat Penyemprot Pestisida ini ialah Toray Carbon Fibre 3K. Material ini digunakan karena memiliki kekuatan namun dengan bobot yang ringan. Berat total dari rangka Alat Penyemprot Pestisida ini sebesar 750 gram.
\end{abstract}

Kata Kunci: Drone, Pestisida, Rangka.

\begin{abstract}
In today's development, technological progress is growing rapidly so that competition in the industrial world itself demands that there be increased innovation to support increased production of a product and with technological advances it can help ease work for the community. One of them is by using drones as a pesticide sprayer. So that it can save time in the process of spraying pesticides on agricultural land. This study aims to design and calculate the construction of a pesticide sprayer with a spraying capacity of 0.5 liters/minute. In the research on design and calculation of pesticide sprayer frame construction with a spraying capacity of 0.5 liters / minute, researchers had to change the initial design of the pesticide sprayer which initially used 6 arms, changed to 4 arms by adjusting the ability of the brushless motor. The frame of this pesticide sprayer uses an octagonal center body with a size of $200 \mathrm{~mm}$ x $190 \mathrm{~mm}$ x $2 \mathrm{~mm}$, an arm with a length of $200 \mathrm{~mm}$ and a diameter of $16 \mathrm{~mm}$, and the distance between the motor and the motor is $600 \mathrm{~mm}$. In the material selection process, calculations are carried out on the results of the design of the pesticide sprayer, such as stress, strain, load distribution and deformation. This is done to determine the strength of the frame design of the pesticide sprayer and to get the results that the design results are suitable for use. The material used in this pesticide sprayer is toray carbon fiber 3k. This material is used because it has strength but with a light weight. The total weight of the frame of this pesticide sprayer is 750 grams.
\end{abstract}

KEYWORDS: Drone, Pesticide, Frame. 


\section{PENDAHULUAN}

Di Indonesia, sektor pertanian merupakan sektor yang mempunyai peranan strategis dalam struktur pembangunan perekonomian nasional. Dan pada perkembangan zaman ini, kemajuan teknologi berkembang dengan pesat sehingga persaingan didalam dunia industri sendiri menuntut agar adannya peningkatan inovasi guna mendukung peningkatan produksi sebuah produk dan dengan adanya kemajuan teknologi dapat membantu meringankan pekerjaan bagi masyarakat. Salah satunya untuk memaksimalkan potensi dari pertanian yang tentunya tidak dapat dilakukan jika sistem pertanian di Indonesia hanya menggunakan alat yang seadanya tanpa menggunakan teknologi yang lebih maju. Salah satunya dalam melakukan penyiraman pestisida oleh petani di Indonesia masih dengan cara konvensional, yaitu dengan menggunakan alat untuk menyiram yang dioperasikan secara konvensional dengan menggunakan tenaga manusia, dan cara itu membutuhkan waktu yang cukup lama dan tenaga yang cukup banyak. Dengan demikian perlu adanya suatu solusi agar permasalahan tersebut dapat diatasi dan dapat membantu para petani dalam meningkatkan produktifitas. Salah satunya dengan memanfaatkan drone sebagai alat penyemprot pestisida. Sehingga dapat menghemat waktu proses penyemprotan pestisida pada lahan pertanian.

\section{TEORI}

\section{Drone}

Drone atau pesawat tanpa awak (Unmanned Aerial Vehicle atau disingkat UAV) adalah sebuah mesin terbang yang berfungsi dengan kendali jarak jauh oleh pilot. Drone mampu mengendalikan dirinya sendiri, menggunakan hukum aerodinamika untuk mengangkat dirinya, bisa digunakan kembali dan mampu membawa muatan baik senjata maupun muatan lainnya.

Jenis-jenis Drone

Berdasarkan baling baling, terdapat 2 jenis Drone, diantaranya:

1. Fixed Wing Drone (Tunggal) Drone jenis ini berbentuk seperti pesawat komersial dan digunakan untuk proses yang cepat, daya jangkau lebih cepat serta lebih luas, biasanya untuk pemetaan (mapping) atau konsepnya seperti scaning.

2. Multicopter Drone (Multi) digunakan oleh pengguna yang ingin membuat video yang bagus sangat cocok memilih drone yang multi copter dikarenakan lebih stabil dan daya angkut serta kekuatan untuk mengangkat beban (kamera) bisa yang lebih berat.

Rangka (Frame) Drone

Salah satu bagian dari sebuah drone yang menyangga semua komponen lainnya pada sebuah Multirotor adalah Frame atau rangka. Pada umumnya material rangka terbuat dari serat karbon (carbon fibre) atau dicetak menggunakan plastik (injection molding), atau dapat juga dari kayu.

\section{METODE PENELITIAN}

Metode yang digunakan dalam penelitian desain dan perhitungan konstruksi alat penyemprot pestisida ini adalah dengan cara mengetahui beban yang diberikan pada konstruksi rangka alat tersebut. Dan menghitung serta mensimulasikannya pada aplikasi solidworks untuk mengetahui kekuatan dari kontruksi alat penyemprot pestisida ini.

\section{HASIL DAN PEMBAHASAN}

\section{Perancangan Rangka}

Spesifikasi rangka pada alat penyemprot pestisida adalah sebagai berikut :

Diameter Lengan : $16 \mathrm{~mm}$

Panjang lengan : $200 \mathrm{~mm}$

Tebal Lengan $\quad: 2 \mathrm{~mm}$

Dimensi Center body : : $190 \mathrm{~mm}$ x $200 \mathrm{~mm}$ x $2 \mathrm{~mm}$

Jarak motor ke motor $\quad$ : $600 \mathrm{~mm}$

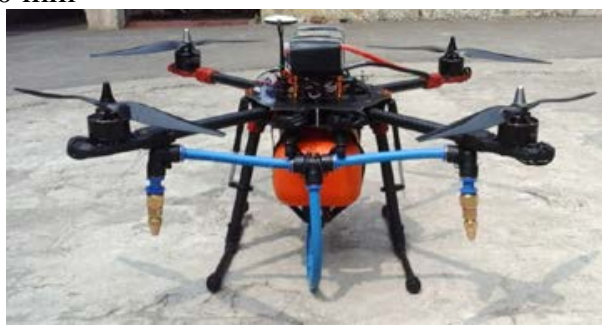

Gambar 1.1 Alat Penyemprot Pestisida 
Perencanaan dan perancangan konstruksi alat penyemprot pestisida dengan kapasitas penyemprotan 0,5 liter/ menit ini dirancang dan dibuat seringkas mungkin unruk mengurangi beban berlebih pada rangka, tetapi dalam perancangan tetap memperhitungkan segala aspek yang diperlukan. Perancangan konstruksi alat penyemprot pestisida ini dibuat dengan mempertimbangkan ukuran dan bobot untuk sebuah quadcopter drone.

\section{Analisa Pembebanan}

Sebelum merancang dan analisa, perlu diketahui terlebih dahulu data tentang berat komponenkomponen yang ditumpu oleh rangka. Berikut ini adalah komponen-komponen yang terdapat pada rangka alat penyemprot pestisida, sekaligus beban yang diterima oleh rangka :

Tabel 2.1 Beban yang diterima rangka

\begin{tabular}{|l|l|l|l|}
\hline No. & Nama Komponen & Jumlah & Berat (gram) \\
\hline 1 & Baterai & 1 & 755 \\
\hline 2 & Motor Brushless & 4 & 524 \\
\hline 3 & ESC & 4 & 36 \\
\hline 4 & Flight Control & 1 & 95 \\
\hline 5 & Pompa & 1 & 40 \\
\hline 6 & Propeller & 4 & 82 \\
\hline 7 & Connector Baterai & 1 & 6.7 \\
\hline 8 & Tabung & 1 & 600 \\
\hline 9 & & 2 & 80 \\
\hline Total berat & Nozzle & & 2218,7 \\
\hline
\end{tabular}

Untuk pembebanan yang diterima rangka adalah 2138,7 gram, dengan itu berat yang diterima rangka dapat dibagi menjadi 3 titik, yaitu :

1. Pembebanan bagian kiri ( F1 )

2. Pembebanan bagian tengah

3. Pembebanan bagian kanan ( F3 )

\section{Perhitungan Beban Secara Teoritis}

Dari data rangka yang diperoleh maka penulis melakukan analisa menggunakan perhitungan secara teoritis sesuai dengan perumusan masalah dan batasan yang diajukan. Awal mula penulis menentukan titik pembebanan dengan asumsi sebagai berikut :

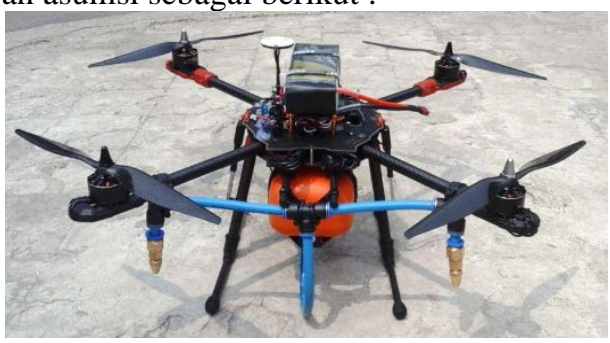

Gambar 3.1 Beban Pada Rangka Alat Penyemprot Pestisida 
Karena beban masing - masing diatas penempatannya simetris, maka secara riil tiap-tiap lengan frame dalam bidang diagonal mendapat pembebanan yang sama.

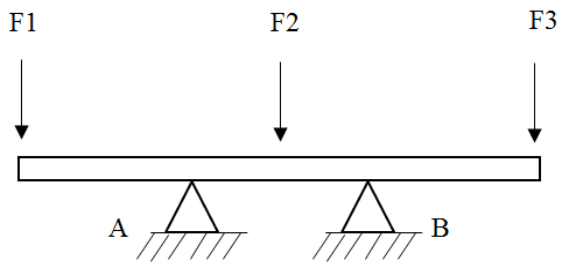

Gambar 3.2 Asumsi penyederhanann pembagian titik berat

Keterangan :

1. A merupakan titik tumpu beban pada alat penyemprot pestisida

2. Beban pada F1, yaitu :

Beban yang diasumsikan pada F1 adalah 343 gram. Jika dikonversikan ke dalam Newton maka diperoleh nilai $3.35 \mathrm{~N}$.

3. Beban pada F2, yaitu :

Beban yang diasumsikan pada F3 adalah 1532,7 gram. Jika dikonversikan ke dalam Newton maka diperoleh nilai $15.03 \mathrm{~N}$.

4. Beban pada F3, yaitu :

Beban yang diasumsikan pada F3 adalah 343 gram. Jika dikonversikan ke dalam Newton maka diperoleh nilai $3.35 \mathrm{~N}$.

Bila dihitung jumlah beban yang diterima oleh rangka sebesar 2218,7 gram, maka bila dikonversikan kedalam Newton menjadi sebesar 21,758 N.

Bila di ilustrasikan, maka pembebanan yang diterima oleh rangka alat tersebut adalah sebagai berikut :

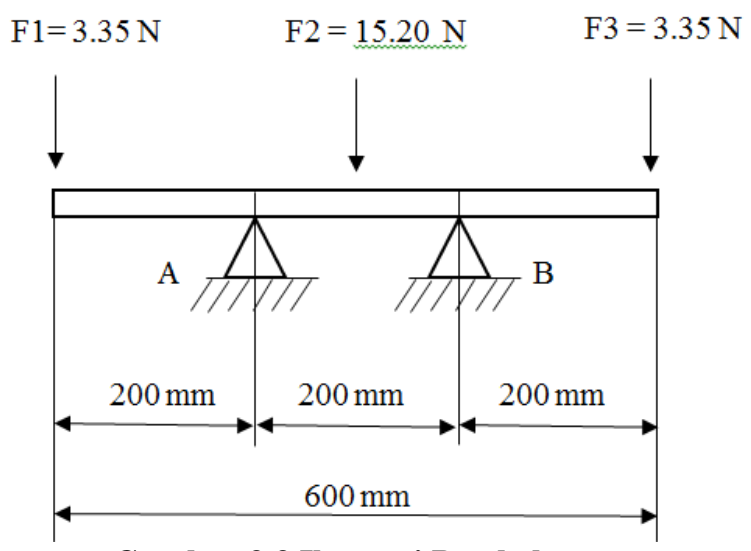

Gambar 3.3 Ilustrasi Pembebanan

Beban Tumpuan :

Bila diketahui :

$\begin{array}{ll}\text { F1 } & : 3.35 \mathrm{~N} \\ \text { F2 } & : 15,03 \mathrm{~N} \\ \text { F3 } & : 3.35 \mathrm{~N}\end{array}$

Distribusi Beban :

$\mathrm{F}_{\text {by }}+\mathrm{F}_{\text {ay }}-(\mathrm{F} 1)-\mathrm{F} 2-(\mathrm{F} 3)=0$

$\mathrm{F}_{\text {by }}+\mathrm{F}_{\mathrm{ay}}=(\mathrm{F} 1)+\mathrm{F} 2+(\mathrm{F} 3)$

$F_{\text {by }}+F_{\text {ay }}=3,35 \mathrm{~N}+15,03 \mathrm{~N}+3,35 \mathrm{~N}$

$\mathrm{F}_{\text {by }}+\mathrm{F}_{\mathrm{ay}}=21,73 \mathrm{~N}$ 


$$
\begin{aligned}
& \sum \mathrm{M}_{\mathrm{A}}=0 \\
& \left(F_{b y} \times 0,2\right)-(F 1 \times 0,2 m)+(F 2 \times 0.1 m)+(F 3 \times 0.4 m)=0 \\
& F_{b y} \times 0,2=(F 1 \times 0,2 m)-(F 2 \times 0.1 m)-(F 3 \times 0.4 m) \\
& F_{b y}=-10,865 \mathrm{~N} \\
& \sum M_{B}=0 \\
& \left(F_{a y} \times 0,2\right)-(F 1 \times 0,4 m)-(F 2 \times 0.1 m)+(F 3 \times 0.2 m)=0 \\
& F_{a y} \times 0,2=(F 1 \times 0,4 m)+(F 2 \times 0.1 m)-(F 3 \times 0.2 m) \\
& F_{a y} \quad=10,865 \mathrm{~N} \\
& F_{b y}+F_{a y} \quad=21,73 \mathrm{~N} \\
& 10,865 \mathrm{~N}+10,865 \mathrm{~N} \quad=21,73 \mathrm{~N} \\
& 21,73 \mathrm{~N}=21,73 \mathrm{~N} \text { ( Hasil sama) }
\end{aligned}
$$

Jadi, dapat disimpulkan bahwa hasil perhitungan diatas sudah benar.

\section{Tegangan Normal}

Tegangan normal maksimum yang terjadi adalah :

Bila diketahui :

$$
\begin{aligned}
& F \max \quad: 15,03 \mathrm{~N} \\
& \text { A } \quad: 29699,58 \mathrm{~mm}^{2}=0.0297 \mathrm{~m}^{2} \\
& \sigma_{\max }=\frac{F_{\max }}{A} \quad=506,06 \mathrm{~N} / \mathrm{m}^{2} \\
& =506,06 \mathrm{~Pa}
\end{aligned}
$$

Untuk perhitungan tegangan ijin, Bila diketahui kekuatan bahan yang digunakan Toray carbon fiber 3K (Tensile Strength) adalah $3530 \mathrm{MPa}$. Kemudian safety factor yang dipilih adalah 6 untuk beban statis dan 4 untuk beban dinamis .

Maka :

$$
\begin{aligned}
\sigma_{\text {ijin }} & =\frac{\sigma_{\text {maxbahan }}}{s_{f 1 x} s_{f 2}} \\
\sigma_{i j i n} & =\frac{\sigma_{\text {maxbahan }}}{s_{f 1 x} s_{f 2}} \\
& =147,08 \mathrm{MPa}
\end{aligned}
$$

Jadi, bila dilihat dari hasil perhitungan teoritis nilai tegangan yang diterima lebih kecil dibandingkan tegangan yang di ijinkan maka desain dapat dikatakan aman.

$$
\sigma_{\max } \leq \sigma_{\text {ijin }}
$$

Hal ini yang menjadikan dasar pemilihan material yaitu Toray Carbon Fiber 3K sebagai material pembuatan rangka Alat Penyemprot Pestisida. Selain material yang ringan, Tegangan ijin yang terdapat pada material Toray Carbon Fiber 3K jauh melebihi tegangan maksimal yang diterima.

\section{Regangan}

Untuk menghitung regangan yang diperlukan sebuah rangka dapat menggunakan persamaan berikut

$$
\begin{aligned}
\varepsilon & =\sigma / \mathrm{E} \\
& =\frac{506,06 \mathrm{~Pa}}{230000 \mathrm{~Pa}} \\
& =2.20 \times 10^{-3}
\end{aligned}
$$

Dari perhitungan diatas maka diperoleh nilai regangan pada kerangka alat penyemprot pestisida sebesar $2.20 \times 10^{-3}$.

\section{Deformasi}

Untuk menghitung deformasi benda karena gaya yang bekerja dapat menggunakan persamaan sebagai berikut : 


$$
\begin{aligned}
\delta l & =\frac{P l}{A E} \\
\delta l & =\frac{15,03 \mathrm{~N} \times 0.2 \mathrm{~m}}{0.0297 \mathrm{~m}^{2} \times 230000 \mathrm{~N} / \mathrm{m}^{2}} \\
& =4,40 \times 10^{-4} \mathrm{~m}
\end{aligned}
$$

\section{Simulasi Menggunakan Software}

Simulasi ini dilakukan untuk mengetahui kekuatan rangka menggunakan software solidwork.

\subsection{Distribusi Beban}

Distribusi beban pada alat penyemprot pestisida dapat dilihat pada gambar dibawah ini :

\section{Gambar 7.1.1. Distribusi Beban Pada Rangka Alat Penyemprot Pestisida}

Gambar diatas menunjukkan distribusi beban yang terdapat pada rangka alat penyemprot pestisida.

\subsection{Simulasi Tegangan}

Simulasi Tegangan pada penelitian desain rangka alat penyemprot pestisida ini menggunakan material Toray Carbon Fiber 3K yang disimulasikan dengan solidwork simulation yang ditunjukkan pada gambar dibawah ini :

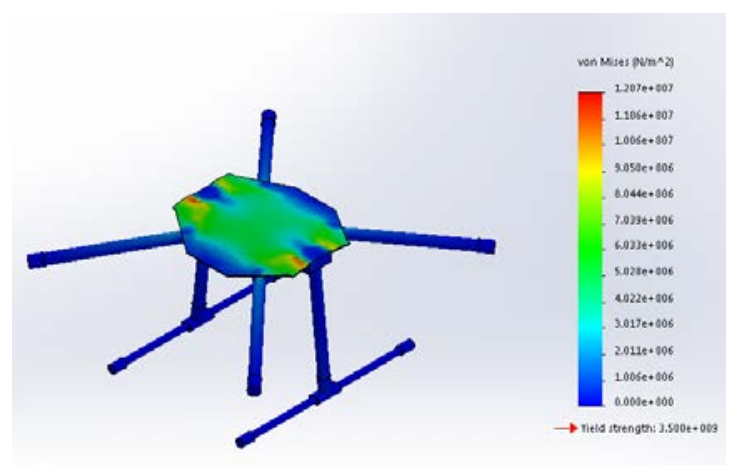

\section{Gambar 7.2.1. Simulasi Tegangan Pada Rangka Alat Penyemprot Pestisida}

Dari hasil diatas, dapat diketahui besar stress maksimum yang didapatkan adalah sebesar $1.207 \mathrm{e}+007$ pada beberapa titik center body dari rangka alat penyemprot pestisida.

\subsection{Simulasi Regangan}

Simulasi Regangan pada penelitian desain rangka alat penyemprot pestisida ini menggunakan material Toray Carbon Fiber 3K yang disimulasikan dengan solidwork simulation yang ditunjukkan pada gambar dibawah ini : 


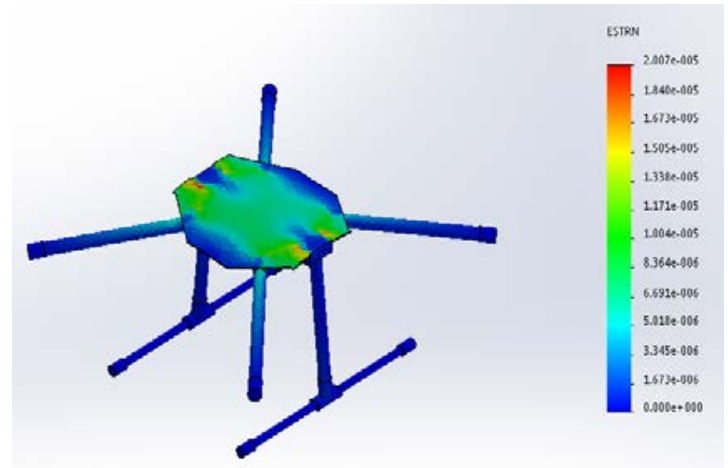

\section{Gambar 7.3.1 Simulasi Regangan Pada Rangka Alat Penyemprot Pestisida}

Dari hasil diatas, dapat diketahui besar strain maksimum yang didapatkan adalah sebesar 2.007e005 pada beberapa titik center body dari rangka alat penyemprot pestisida.

\subsection{Simulasi Deformasi}

Simulasi Deformasi pada penelitian desain rangka alat penyemprot pestisida ini menggunakan material Toray Carbon Fiber 3K yang disimulasikan dengan solidwork simulation yang ditunjukkan pada gambar dibawah ini :

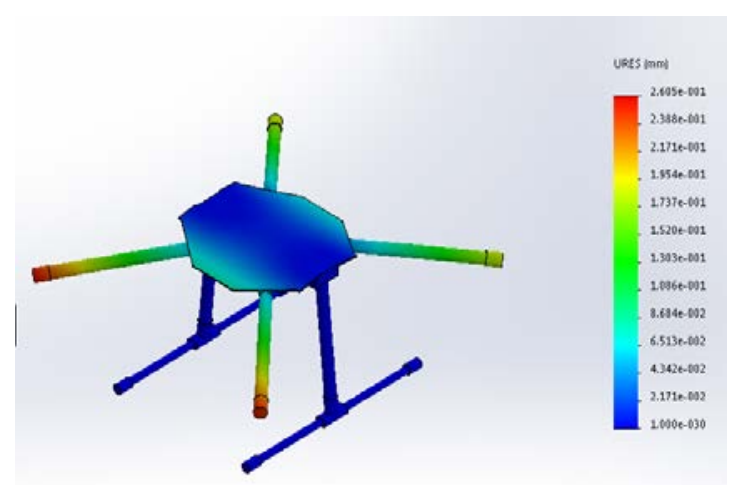

\section{Gambar 7.4.1 Simulasi Deformasi Pada Rangka Alat Penyemprot Pestisida}

Dari hasil diatas, dapat diketahui besar deformasi maksimum yang didapatkan adalah sebesar 2.065e-001 mm pada bagian lengan tempat nozzle berada dari rangka alat penyemprot pestisida.

\subsection{Simulasi Safety Factor}

Simulasi Safety Factor pada penelitian desain rangka alat penyemprot pestisida ini menggunakan material Toray Carbon Fiber 3K yang disimulasikan dengan solidwork simulation yang ditunjukkan pada gambar dibawah ini :

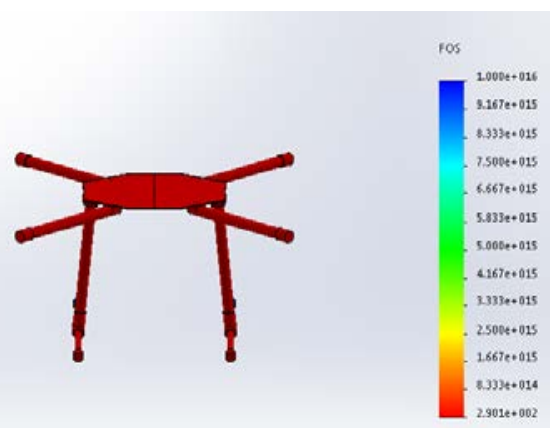

Gambar 7.5.1 Simulasi Safety Factor Pada Rangka Alat Penyemprot Pestisida 
Dari hasil diatas, didapatkan Safety factor di atas dikatakan aman/safe untuk digunakan, karena menghasilkan safety factor yang lumayan besar pada titik minimumnya yaitu $\mathbf{2 . 9 0 1 e + 0 0 2}$.

\section{KESIMPULAN}

Berikut ini merupakan kesimpulan dari proses penelitian Desain dan Perhitungan Konstruksi Rangka Alat Penyemprot Pestisida Dengan Kapasitas Penyemprotan 0,5 liter / menit :

1. Dalam penelitian Desain dan Perhitungan Konstruksi Rangka Alat Penyemprot Pestisida Dengan Kapasitas Penyemprotan 0,5 liter / menit, Pada rangka Alat penyemprot Pestisida ini menggunakan center body berbentuk persegi delapan dengan ukuran 200 mm x 190 mm x 2 mm, lengan dengan panjang $200 \mathrm{~mm}$ dan diameter $16 \mathrm{~mm}$, dan jarak antar motor ke motor ialah 600 mm.

2. Material yang digunakan pada Alat Penyemprot Pestisida ini ialah Toray Carbon Fibre $3 \mathrm{~K}$. Material ini digunakan karena memiliki kekuatan namun dengan bobot yang ringan, yang dimana bobot dari material merupakan faktor utama dalam pemilihan material karena akan mempengaruhi daya angkat dari motor brushless. Berat total dari rangka Alat Penyemprot Pestisida ini sebesar 750 gram.

3. Sebelum proses pemilihan bahan, penulis melakukan perhitungan terhadap hasil rancangan Alat Penyemprot Pestisida. Hal ini dilakukan untuk mengetahui kekuatan dari rancangan rangka Alat Penyemprot Pestisida dan mendapatkan hasil bahwa hasil rancangan tersebut telah layak untuk digunakan.

\section{SARAN}

Berikut ini adalah saran untuk penulis sendiri dan juga untuk penelitian selanjutnya :

1. Dalam proses desain dan perhitungan konstruksi rangka Alat Penyemprot Pestisida ini yang perlu diperhatikan adalah dalam menghitung beban yang diterima oleh rangka dan juga pemilihan bahan yang sesuai dengan kebutuhannya.

2. Untuk hasil lebih maksimal, perlu adanya penambahan ukuran rangka agar dapat memasang ukuran tangki yang lebih besar, sehingga dapat memaksimalkan kekuatan angkat yang dihasilkan oleh motor brushless.

\section{DAFTAR PUSTAKA}

[1] D. Cook, Robert., 1990, Konsep dan Aplikasi Metode Elemen Hingga. Terjemahan Ir. Bambang Suryoatmono, PT ERESCO, Jakarta.

[2] Irawan, Agustinus Purwa, 2009, Diktat Elemen Mesin, Universitas Tarumanegara, Jakarta.

[3] Syatiri, Ahmad, dkk, 2014, Pestisida Dalam Pertanian, Universitas Islam Riau, Pekanbaru.

[4] Weaver .W.Jr., Johnston, P.R., 1993, Elemen Hingga Untuk Analisis Struktur, Edisi kedua, Eresco, Bandung.

[5] Yunus, Asyari Darami, 2010, Diktat Kekuatan Material, Universitas Darma Persada, Jakarta.

[6] Santoso, Djarot Wahju, Kris Hariyanto, 2017, Pengembangan Sistem Penyemprotan Pada Platform Pesawat Tanpa Awak Berbasis Quadcopter Untuk Membantu Petani Mengurangi Biaya Pertanian Dalam Mendorong Konsep Pertanian Pintar (Smart Farming), Jurnal Ilmiah Bidang Teknologi, ANGKASA Volume IX, Nomer 2, November 2017.

[7] Sayuti, Syahril, Muhammad Soffan Hakim, 2016, Perancangan Dan Pembuatan Rangka Drone Yang Ekonomis Dan Praktis, Prosiding Seminar Nasional Aplikasi Sains \& Teknologi 26 November 2016

[8] Yudhana, Anton, Miko Wardani, 2017, Rancang Bangun Penyemprot Pestisida Untuk Pertanian Padi Berbasis Quadcopter, Jurnal Ilmu Teknik Elektro Komputer dan Informatika (JITEKI) Vol. 3, No. 2, Desember 2017.

[9] http://eprints.polsri.ac.id/3333/3/File\%20III.pdf (diakses pada tanggal 22 Juli 2018)

[10] https://www.toraycma.com/page.php?id=661 (diakses pada tanggal 3 Agustus 2018) 